\title{
DSC Study of Transitions Involved in Thermal Treatment of Foamable Mixtures of PE and EVA Copolymers with Azodicarbonamide
}

\author{
J. A. Reyes-Labarta, M. M. Olaya, A. Marcilla \\ Departamento Ingeniería Química, Universidad de Alicante, Apdo. 99, Alicante 03080, Spain
}

Received 20 May 2005; accepted 16 December 2005

DOI 10.1002/app.23969

Published online in Wiley InterScience (www.interscience.wiley.com).

\begin{abstract}
The transitions and reactions involved in the thermal processing of binary mixtures of polyethylene and poly(ethylene-co-vinyl acetate) copolymers with different concentrations of a foaming agent (azodicarbonamide) were studied using differential scanning calorimetry (DSC). The effect of $\mathrm{ZnO}$ as a kicker also was discussed. The temperature at the maximum rate and the heat evolved were measured for all the processes-melting, transitions, and reactions-all
\end{abstract}

the mixtures prepared were measured and compared. Azodicarbonamide decomposed differently depending on the polymeric matrix. These data can be very useful for the plastic processing industry. (c) 2006 Wiley Periodicals, Inc. J Appl Polym Sci 000: 000-000, 2006

Key words: polymer foam; azodicarbonamide; differential scanning calorimetry (DSC); polyethylene (PE); EVA

\section{INTRODUCTION}

The family of low-density microcellular compounds obtained by the foaming and crosslinking of poly(ethylene-co-vinyl acetate) (EVA) copolymer has a large field of commercial applications. Products such as the soles of sport shoes, toys, nautical buoys, gymnasium floors, and hygienic stable floors. are typical examples indicating its wide range of uses from its reduction in density being turned directly into cost savings and products of greater value.

The industrial process of these foamed products consists basically in the injection of a multicomponent formulation including a polymeric matrix, a crosslinking agent, a blowing or foaming agent and a kicker into a heated mold under a high clamping pressure. Colorants, stabilizers, and other additives are frequently used to obtain the final properties of the product. After the residence time required to produce the corresponding crosslinking reactions and decomposition of the blowing agent, the fast opening of the heated mold causes an instantaneous expansion of the gases encapsulated inside the polymeric matrix. Finally, the molded piece shrinks along the cooling process until it reaches the final dimensions.

Azodicarbonamide (ADC) is frequently used in the production of EVA and polyethylene (PE) foams

\footnotetext{
Correspondence to: A. Marcilla (antonio.marcilla@ua.es).

Contract grant sponsor: Generalitat Valenciana; contract grant number: GV01-42 and GR01-36.
}

Journal of Applied Polymer Science, Vol. 000, 000-000 (2006)

(c) 2006 Wiley Periodicals, Inc. because its decomposition liberates a high volume of gas, which is trapped in the melt. ${ }^{1-3}$ This foaming agent is normally used in combination with a crosslinking agent to produce the required final product. The primary decomposition of this chemical, according to Stevens and Emblem ${ }^{4}$ and Laber, ${ }^{5}$ goes through the competitive and exothermic reaction pathways shown in Figure 1. The products of these reactions are solids (urazol and hydrazodicarbonamide) and a gaseous mixture of nitrogen, carbon monoxide, cyanic acid, and ammonia. Depending on the process conditions, different products may be favored over others. ${ }^{2,4,6}$ Typical parameters for the commercial azodicarbonamides provided by the suppliers are: purity and amount of gases (gas yield) evolved in an isothermal process at $210^{\circ} \mathrm{C}$ for 15 min collected in diisooctyl phthalate (DOP). ${ }^{7,9}$

Differential scanning calorimetry (DSC) is a commonly used technique to study and characterize the thermal transitions undergone by polymers, such as melting, crystallization, and reordering in their structure $^{10-17}$

In previous works, ${ }^{18-20}$ the thermal transitions and crystallinity of a commercial EVA and PE and their binary mixtures were studied by DSC, and the methodology used to perform the kinetic study of the data was discussed.

In the present study, different mixtures of a polymer (EVA or PE) and a foaming agent (ADC) at different concentrations were investigated using the DSC technique to establish the interactions among the polymeric matrix and the ADC. Some mixtures including $\mathrm{ZnO}$ as a kicker were also studied. Both the 
i) 2

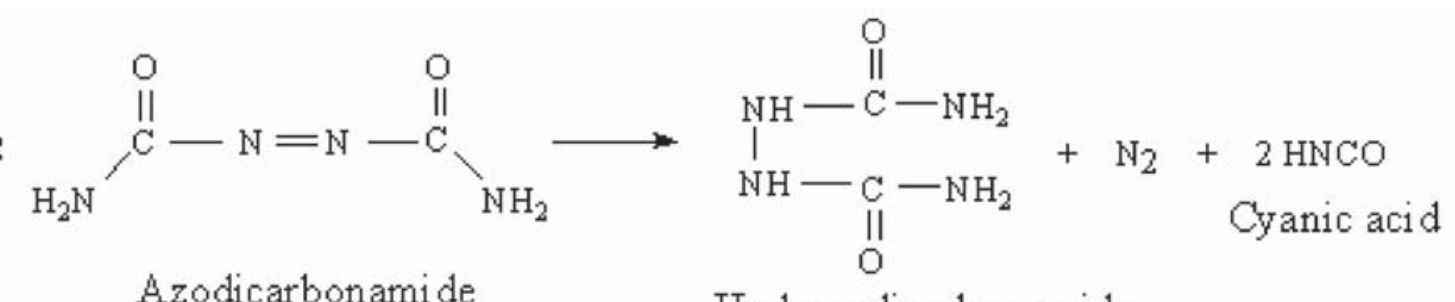

Azodicarbonamide

Hydrazodicarbonamide

ii)<smiles>NC(=O)N=NC(N)=O</smiles>

Azodicarbonamide<smiles>C1CCCCC1</smiles><smiles>O=c1[nH][nH]c(=O)[nH]1</smiles><smiles></smiles><smiles>NC(=O)N=NNC(N)=O</smiles>

Hydrazodicarbonamide

Figure 1 Decomposition reactions for azodicarbonamide. ${ }^{4,5}$

components and the compositions of the mixtures studied were typical in commercial formulations.

The analysis presented in this article allows better knowledge of the foaming phenomenon: quantification of the heat involved in the industrial processing of foamed products and very useful information for optimizing the process, cycles, and formulations to be used.

\section{EXPERIMENTAL}

\section{Materials}

The polymers used were low-density polyethylene AQ3 (PE003 ALCUDIA ${ }^{\circledR}$ ) and EVA PA-539 ALCUDIA ${ }^{\circledR}$ AQ4 copolymer, both supplied by REPSOL YPF ${ }^{\circledR}$. Tables T1, T2 I and II show the properties of these two polymers according to the supplier.

TABLE I

Technical Data for LDPE ALCUDIA ${ }^{\circledR}$ PE003 (Repsol YPF)

\begin{tabular}{lr}
\hline \multicolumn{1}{c}{ Property } & Value \\
\hline MFI $(\mathrm{g} / 10 \mathrm{~min})$ & 2 \\
Vicat temperature $\left({ }^{\circ} \mathrm{C}\right)$ & 92 \\
Crystallinity $(\%)$ & 44 \\
Density at $23^{\circ} \mathrm{C}\left(\mathrm{kg} / \mathrm{m}^{3}\right)$ & 920 \\
Melting temperature $\left({ }^{\circ} \mathrm{C}\right)$ & 113 \\
\hline
\end{tabular}

The foaming agent was azodicarbonamide Unicell$\mathrm{D}^{\mathbb{R}}$ supplied by LEDEX ${ }^{\mathbb{R}}$ S.A. (Table III).

\section{Procedure}

Binary mixtures of EVA or PE with three concentrations of ADC typically used in industrial formulations [1,2, and 4 parts per 100 parts of resin (phr) or $0.99,1.96$, and $3.85 \mathrm{wt} \%$ ] were studied. Also, ternary mixtures were considered by adding $\mathrm{ZnO}$ (1.5 phr). The composition and corresponding code of each mixture studied are shown in Table IV.

TABLE II

Technical Data for EVA ALCUDIA ${ }^{\circledR}$ PA-539 (Repsol YPF)

\begin{tabular}{llc}
\hline & \multicolumn{1}{c}{ Property } & Value \\
\hline General & Melt flow index $(\mathrm{g} / 10 \mathrm{~min})$ & 2 \\
& Density at $23^{\circ} \mathrm{C}\left(\mathrm{kg} / \mathrm{m}^{3}\right)$ & 937 \\
\multirow{5}{*}{ Mechanical } & 18 \\
& Vinyl acetate $(\%)$ & 17 \\
& Tensile strength at break $(\mathrm{MPa})$ & 5 \\
& Tensile strength at yield $(\mathrm{MPa})$ & 750 \\
& Elongation at break $(\%)$ & 90 \\
& Shore A hardness & 38 \\
Thermal & Shore D hardness & 64 \\
& Vicat temperature $\left({ }^{\circ} \mathrm{C}\right)$ & -30 to -35 \\
& Brittleness temperature $\left({ }^{\circ} \mathrm{C}\right)$ & 90 \\
\hline
\end{tabular}


TABLE III

Technical Data for Azodicarbonamide Unicell-D ${ }^{\circledR}$ (LEDEX S.A.)

\begin{tabular}{lc}
\hline \multicolumn{1}{c}{ Property } & Value \\
\hline ADC $($ wt $\%)$ & 91.1 \\
Decomposition temperature $\left({ }^{\circ} \mathrm{C}\right)$ & 187 \\
Ashes $(\%)$ & 5.85 \\
Gas yield $\left(\mathrm{cm}^{3} / \mathrm{g}\right)$ (isothermal at $210^{\circ} \mathrm{C}$ for $\left.15 \mathrm{~min}\right)$ & 160 \\
Density $\left(\mathrm{g} / \mathrm{cm}^{3}\right)$ & 1.65 \\
\hline
\end{tabular}

The mixtures were prepared prior to the DSC experiments in a Brabender ${ }^{\circledR}$ Plasticorder PL 2000 extruder at $125^{\circ} \mathrm{C}$ and $20 \mathrm{rpm}$, using a single screw. These conditions were chosen so that the mixtures would achieve good homogenization but decomposition of the foamed agent would be avoided. After the extrusion die, the mixture discharged was cut into pellets, immersed in a water bath, and dried at room temperature.

Small aliquots of the samples prepared ( 8 or $9 \mathrm{mg}$ ) were encapsulated in aluminum pans and analyzed in a Perkin Elmer ${ }^{\circledR}$ DSC7 in a temperature range from 313 to $573 \mathrm{~K}$ increasing $10^{\circ} \mathrm{C} / \mathrm{min}$ (first run). The sample was then cooled to $293 \mathrm{~K}$, and a second run was performed at the same heating rate in order to analyze the interaction between the polymer and the foaming agent, not only during the foaming process (first run) but also in the final foamed product (second run).

The atmosphere used was nitrogen with a flow rate of $45 \mathrm{~mL} / \mathrm{min}$ (STP). All the experiments presented in this article were carried out three times, with very similar results obtained.

To determine the density of the final foamed products, the mixtures prepared in the extruder were pressed in a heated plate press (MECAMAQ ${ }^{\circledR}$ DE200 ) at $408 \mathrm{~K}$ for $10 \mathrm{~min}$ in order to carry out the foaming reaction.

\section{RESULTS AND DISCUSSION}

F2 Figure 2(a) shows the DSC curve of the azodicarbonamide used in this work from 300 to $550 \mathrm{~K}$. This curve showed two overlapped and exothermic peaks of ADC thermal decomposition ( $\mathrm{p} 1$ and $\mathrm{p} 2$ ) and one endothermic peak of ADC thermal decomposition (p3), which indicates that the complete thermal decomposition of the ADC took place in different steps. The first two exothermic peaks should correspond to the primary decomposition of the ADC $\left(\mathrm{H}_{4} \mathrm{~N}_{4} \mathrm{C}_{2} \mathrm{O}_{2}\right)$, producing solids and gases with the accepted scheme of the three competitive reactions shown in Figure 1. These reactions were competitive and therefore produced the initial, exothermic, and overlapped $\mathrm{p} 1$ and $\mathrm{p} 2$ peaks shown in Figure 2 at global step, responsible for the endothermic p3 peak at $525 \mathrm{~K}$, consisted ofthe final decomposition of the solids produced in the first decomposition step $\left(\mathrm{H}_{3} \mathrm{~N}_{3} \mathrm{C}_{2} \mathrm{O}_{2}\right.$ and $\left.\mathrm{H}_{6} \mathrm{~N}_{4} \mathrm{C}_{2} \mathrm{O}_{2}\right)$.

Figures 3-6 and 7-10 show the DSC curves for the three mixtures of PE-ADC and EVA-ADC studied, respectively.

\section{PE-ADC mixtures}

The first run for the PE-ADC binary mixtures (Figs. 3-5) shows a first endothermic peak at $386 \mathrm{~K}$, corresponding to the melting process of the PE matrix. Because the ADC was still unaltered at this temperature, the temperature and also the heat corresponding to this PE melting process were practically the same as those obtained for pure PE (Table VI). ${ }^{18}$

After the melting of the polymer, two more peaks appeared in the first run of the DSC curves that corresponded to the exothermic (primary) and endothermic (secondary) decomposition of the ADC. The first two exothermic processes clearly observed in the pure ADC (p1 and p2 in Fig. 2) had become, as shown in Figures 3-5, totally overlapped in a wide peak $(\mathrm{p} 1+\mathrm{p} 2)$ that appeared at higher temperatures (i.e., temperatures of the maximum rate) than the second exothermic peak (p2) in the DSC curve of the pure ADC (Tables V and VI). Nevertheless, this peak would correspond mainly to the second process of the decomposition of ADC (i.e., the more marked decomposition of the pure ADC shown by DSC). The peak temperatures of this wide exothermic process shown in the DSC curves of the three PE-ADC samples decrease as the concentration of ADC increased, and with a concentration of $4 \mathrm{phr}$ the temperature reached $465.3 \mathrm{~K}$, which is close to the $460 \mathrm{~K}$ of pure ADC. In the same way, the endothermic process (p3) also appeared at higher temperatures in the PE-ADC mixtures, and its peak temperature decreased with decreases in the ADC content of the sample. Figure 6 shows the $T_{\max }$ of these processes as a function of the ADC content. Also shown is the temperature of

TABLE IV

Compositions and Codes of PE-ADC and EVA-ADC Mixtures

\begin{tabular}{ccccl}
\hline \multicolumn{4}{c}{ Composition (phr) } & \\
\cline { 1 - 3 } PE & EVA & ADC & ZnO & \multicolumn{1}{c}{ Code } \\
\hline 100 & & 1 & & P-A(1) \\
100 & & 2 & & P-A(2) \\
100 & & 4 & & P-A(4) \\
100 & & 2 & 1.5 & P-A(2)-Z(1.5) \\
& 100 & 1 & & E-A(1) \\
& 100 & 2 & & E-A(2) \\
& 100 & 4 & & E-A(4) \\
& 100 & 2 & 1.5 & E-A(2)-Z(1.5) \\
\hline
\end{tabular}




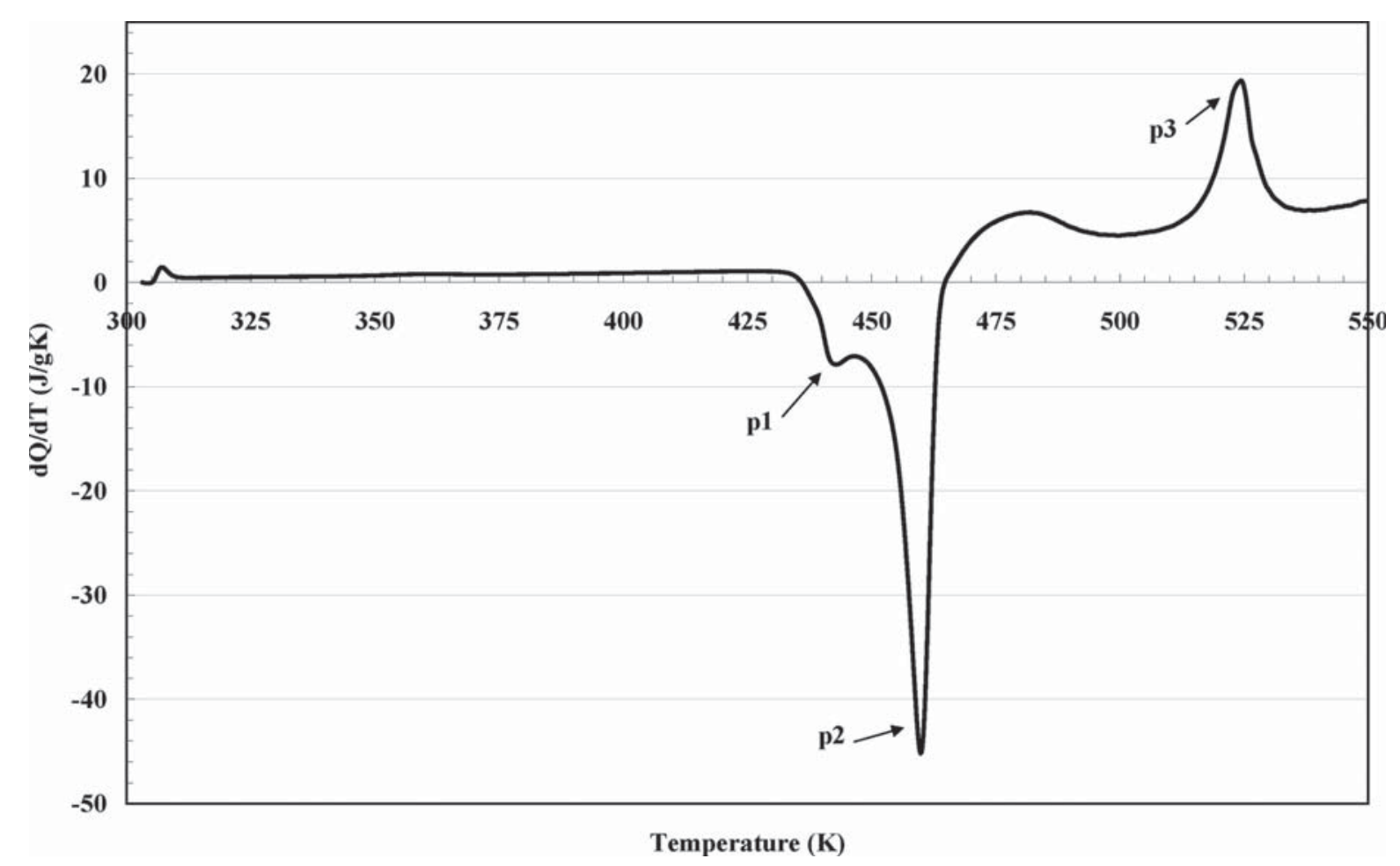

Figure 2 DSC curve for the azodicarbonamide Unicell-D ${ }^{\circledR}$ (LEDEX S.A. ${ }^{\circledR}$ ).

the pure ADC, which would correspond to the asymptotic value for an infinite ADC content.

The displacement of the peaks associated with ADC thermal decomposition of the PE-ADC samples compared with those of the pure ADC might be explained by two different effects.

One was the negative effect of the polymeric matrix on heat transfer inside the sample contributing to the delay of the peaks occurring in the samples with PE compared with in pure ADC.

The other was that the heterogeneous reaction (reaction iii of the azodicarbonamide degradation reactions shown in Fig. 1) possible introduced an autoaccelerating effect ${ }^{1,2,6,21}$ when the concentration of ADC in the sample increased because of the higher probability of a reaction occurring (as result of longer contact time) between the unreacted ADC and the HNCO gas generated from reactions $i$ and ii, shown in Figure 1. This reaction could have accelerated the global decomposition of the ADC and produced the observed shift to lower temperatures.

Another aspect worth mentioning is that the DSC showed different extensions of the reactions of ADC decomposition of the binary PE-ADC mixtures (Figs. $3-5)$. Whereas the heat evolved $\left(\mathrm{J} / \mathrm{g}_{\text {sample }}\right)$ in the first wide exothermic processes $(\mathrm{p} 1+\mathrm{p} 2)$ of the PE-ADC samples increased lineally with ADC content (Table $\mathrm{VI})$, the heat corresponding to the last endothermic process (p3) remained almost constant regardless of ADC content.
In contrast, a progressive increase of the final base line slope occurred when the ADC concentration of the sample was increased (Figs. 3-5). This phenomenon can be explained by the heat transfer within the sample. When ADC content increased, a greater amount of the products of degradation products was obtained (solid residues and encapsulated gases, yielding a progressively more foamed sample), which could have decreased the apparent thermal conductivity and increased the apparent heat capacity.

\section{EVA-ADC mixtures}

DSC curves for a typical EVA copolymer showed two endothermic and overlapped peaks, at 321 and $344 \mathrm{~K}$, corresponding to the initial transition and the melting process of the vinyl acetate (VA) domains, and a third endothermic peak at $386 \mathrm{~K}$ (much smaller), corresponding to the melting of the ethylene domains of the EVA copolymer.

TABLE V

DSC Results for Pure ADC

\begin{tabular}{clc}
\hline Primary decomposition & $\Delta H_{\mathrm{p} 1}(\mathrm{~J} / \mathrm{g})$ & -18.33 \\
(exothermic) & $T_{\mathrm{peak}}(\mathrm{K})$ & 442.8 \\
& $\Delta H_{\mathrm{p} 2}(\mathrm{~J} / \mathrm{g})$ & -260.52 \\
& $T_{\mathrm{peak}}(\mathrm{K})$ & 460.0 \\
Secondary decomposition & $\Delta H_{\mathrm{p} 3}(\mathrm{~J} / \mathrm{g})$ & 107.71 \\
(endothermic) & $T_{\text {peak } \mathrm{p} 3}(\mathrm{~K})$ & 525 \\
\hline
\end{tabular}




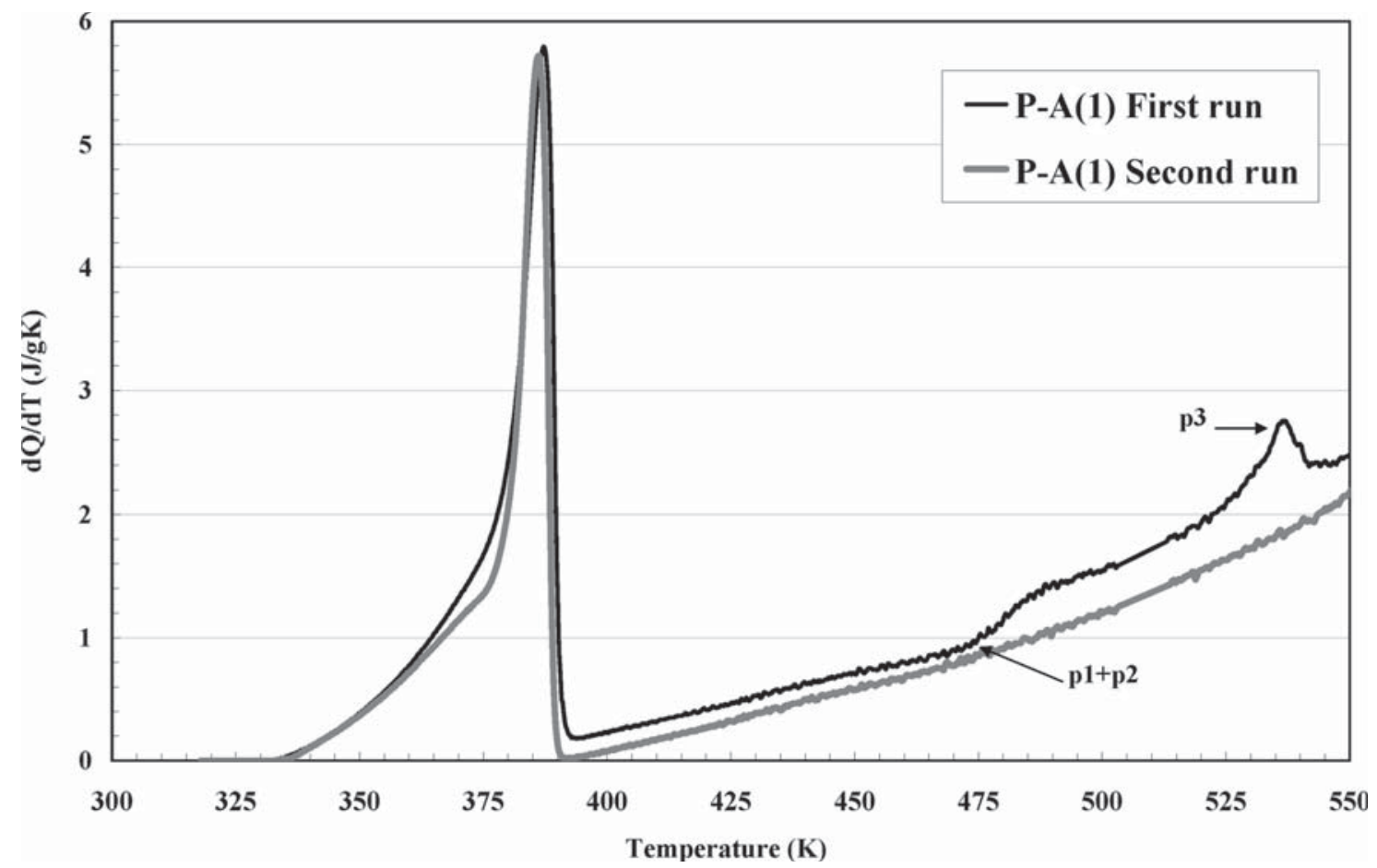

Figure 3 DSC results (first and second runs) for the PE-ADC (1 phr) binary mixture.

The peaks corresponding to the thermal transitions of the polymeric matrix for the EVA-ADC binary samples studied (Figs. 7-9 and Table VII) were similar (reaction temperatures and heats) to those obtained for the pure polymer. ${ }^{1}$
Regarding ADC thermal decomposition, the sample with the lower ADC content, E-A(1), showed only two peaks: one exothermic peak, at $464 \mathrm{~K}$, and the other, an endothermic peak, at $532 \mathrm{~K}$ (Fig. 7), whereas the samples with 2 and $4 \mathrm{phr}$ of ADC (Figs. 8 and 9,

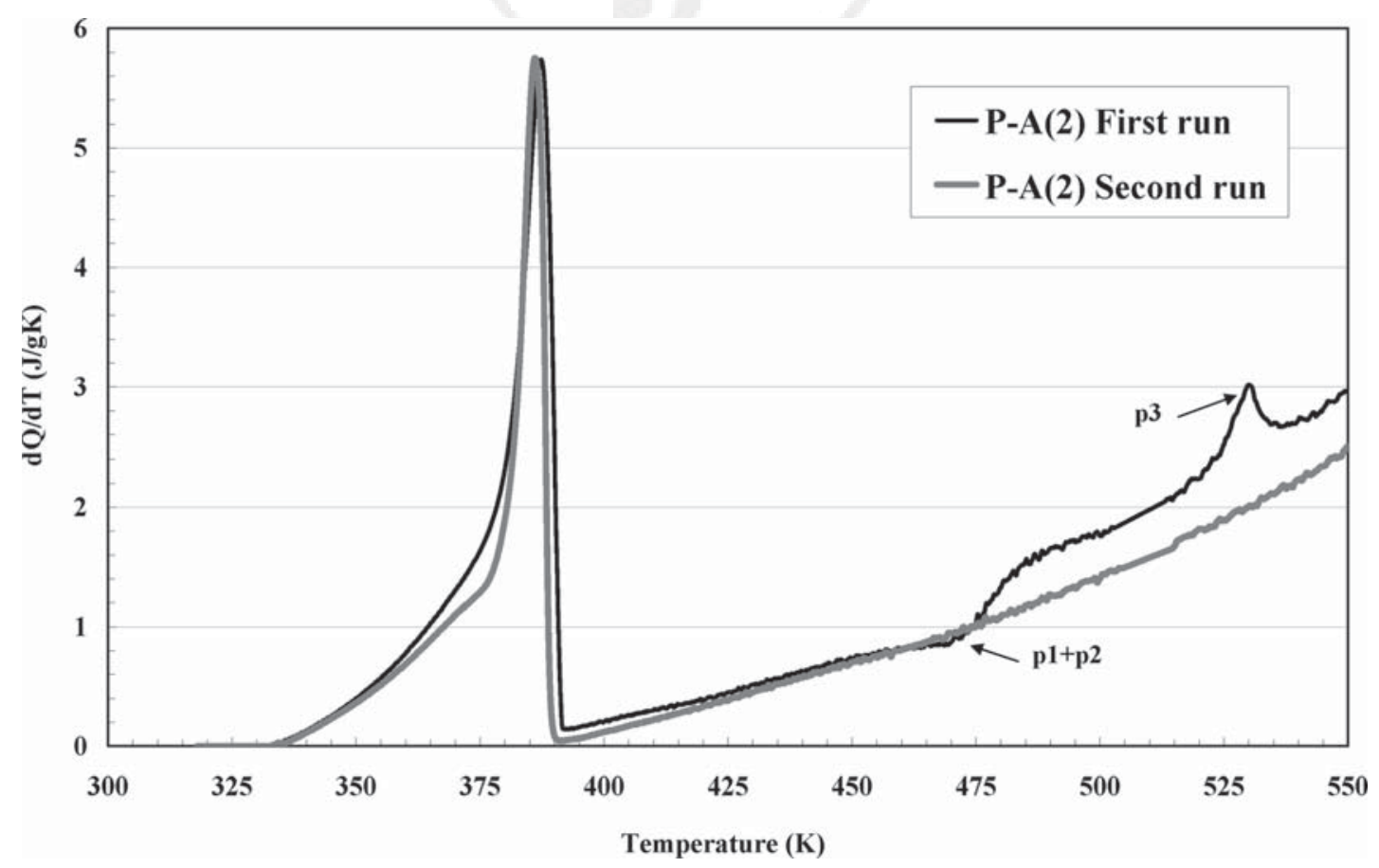

Figure 4 DSC results (first and second runs) for the PE-ADC (2 phr) binary mixture. 


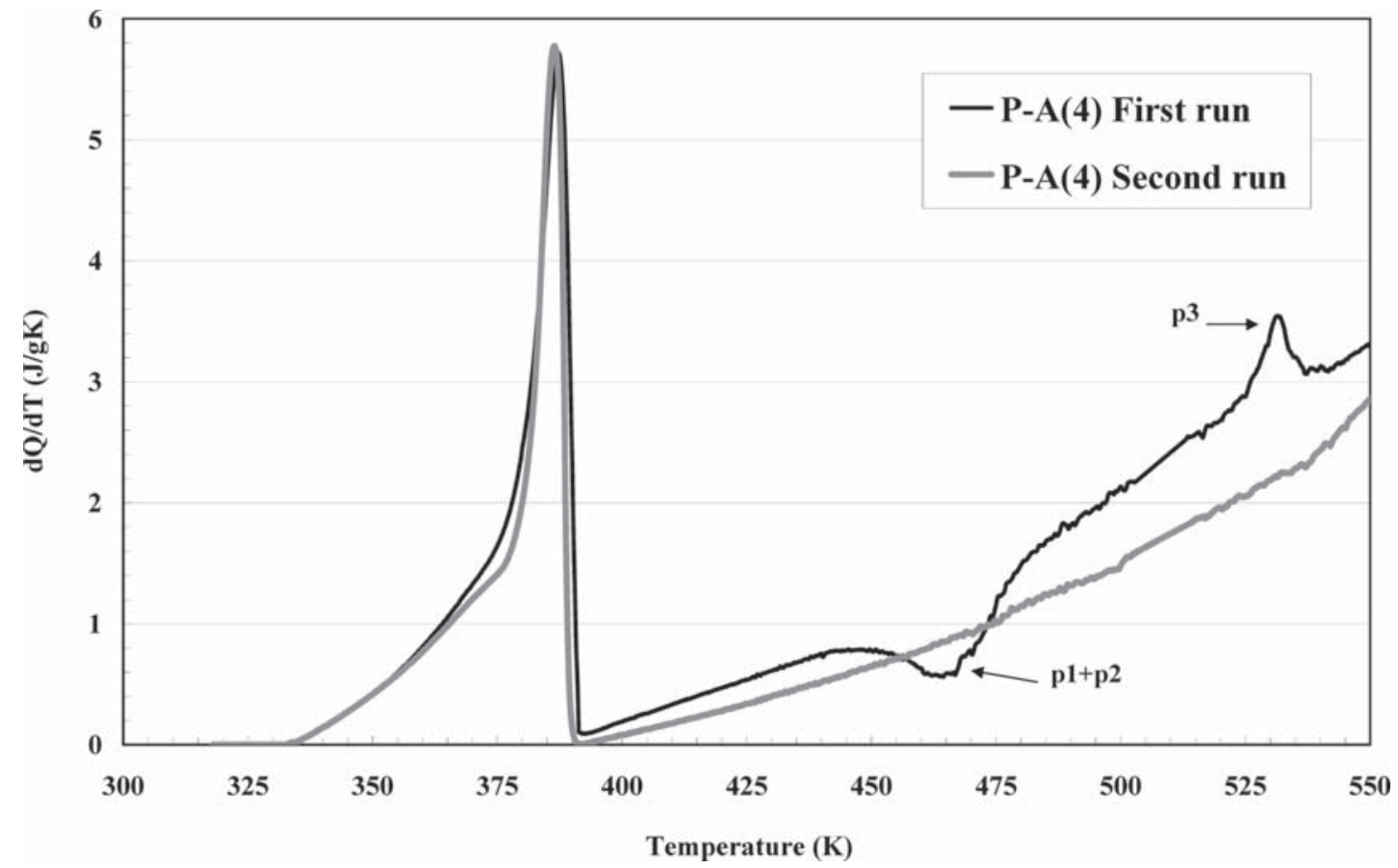

Figure 5 DSC results (first and second runs) for the PE-ADC (4 phr) binary mixture.

respectively) showed three decomposition peaks (two exothermic and one endothermic) as did the pure ADC (Fig. 2).

The peak temperatures showed an evolution rather different from that of the PE-ADC mixtures (Figs. 6 and 10). With an EVA-ADC sample with a low con- centration of ADC (Figs. 7 and 8), the first exothermic peak ( 1 1) was much more evident than the second (p2), unlike with the pure ADC (Fig. 2). The temperature of the maximum rate of this $\mathrm{p} 1$ process passed through the minimum for the ADC concentration (Fig. 10). The effect of the polymeric matrix on heat

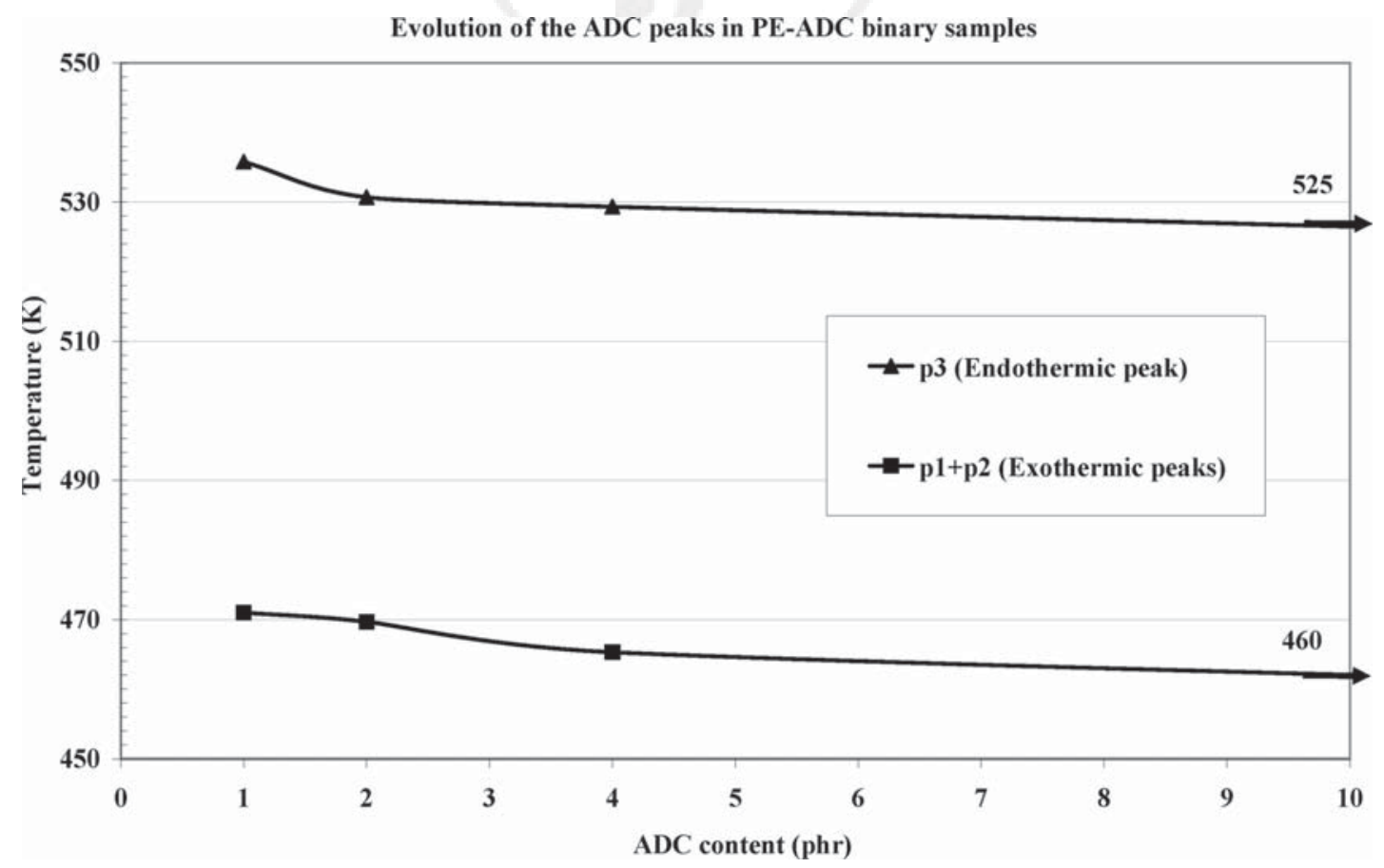

Figure 6 Evolution of the peak temperatures for the ADC thermal decomposition in PE-ADC samples. 


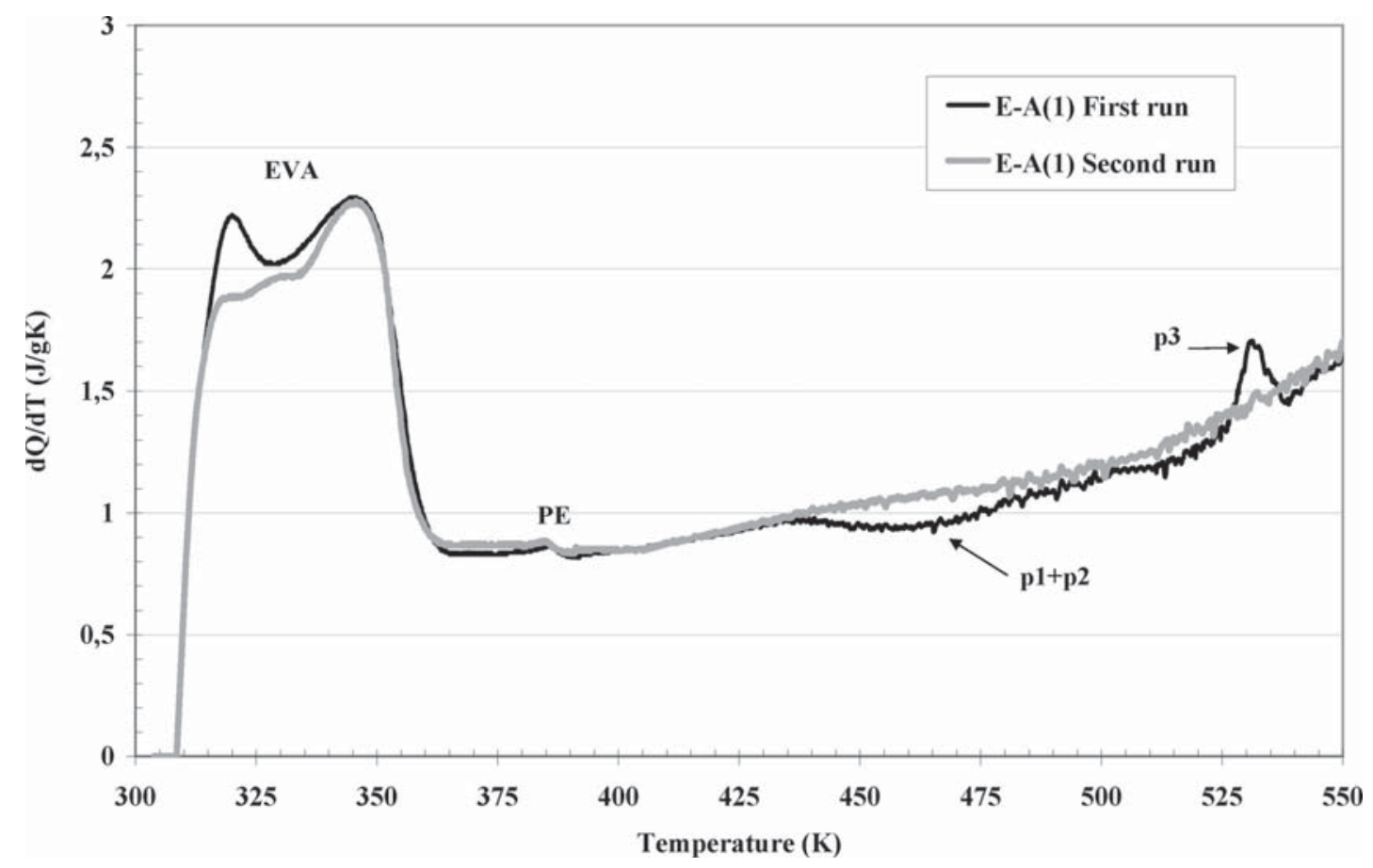

Figure 7 DSC results (first and second runs) for the EVA-ADC (1 phr) binary mixture.

transfer inside the sample was evident, as already noted, but in this case, the EVA also seemed to alter the mechanism of primary exothermic thermal decomposition of the ADC (the $\mathrm{p} 1$ and $\mathrm{p} 2$ peaks had different relative intensities), which apparently went through paths different than those of the pure ADC and the PE-ADC mixtures.

With respect to the heat evolved, and assuming that, according to the trend observed, the heat evolved in the overlapped peak in the experiment with $1 \mathrm{phr}$

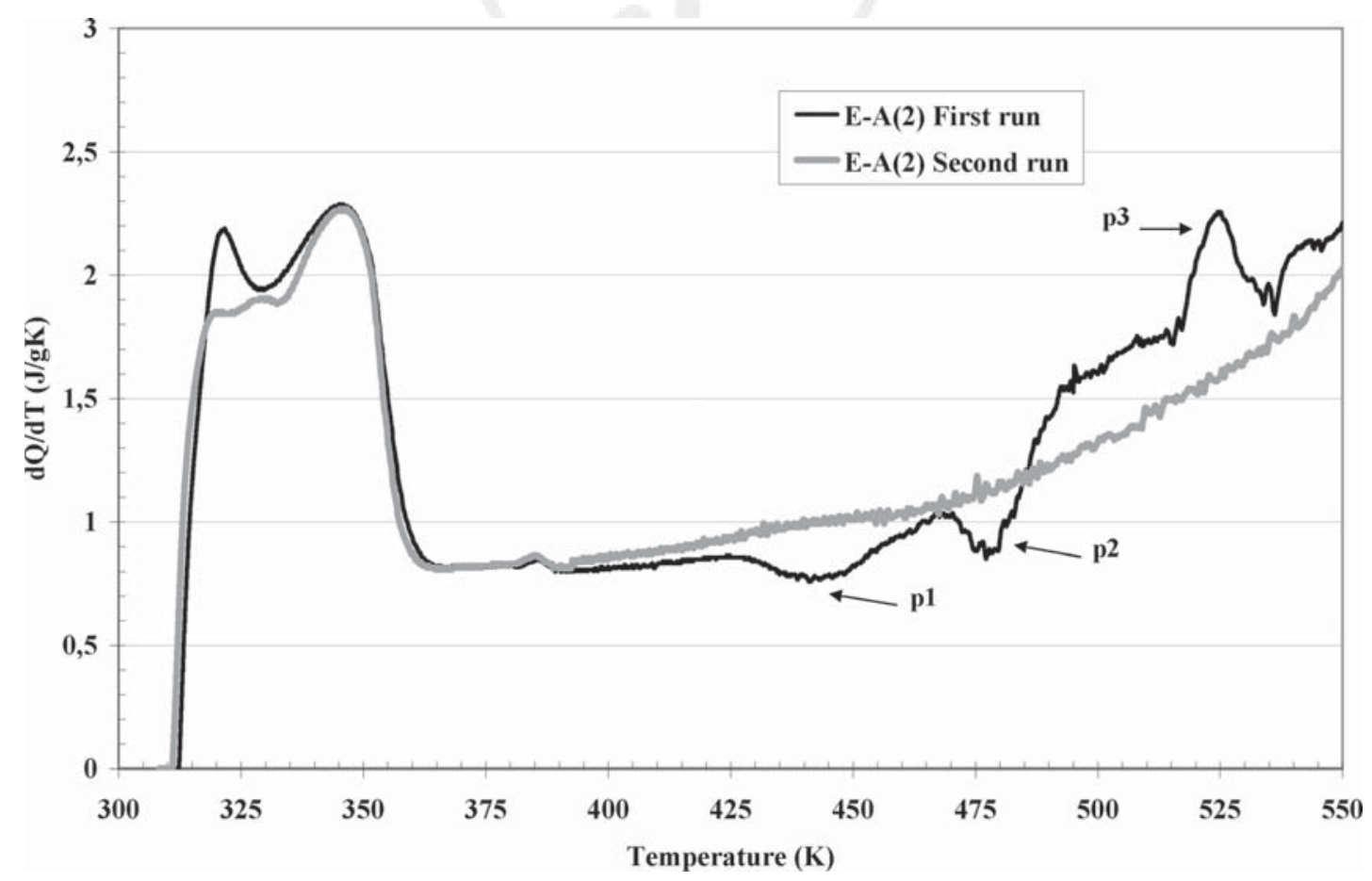

Figure 8 DSC results (first and second runs) for the EVA-ADC (2 phr) binary mixture. 


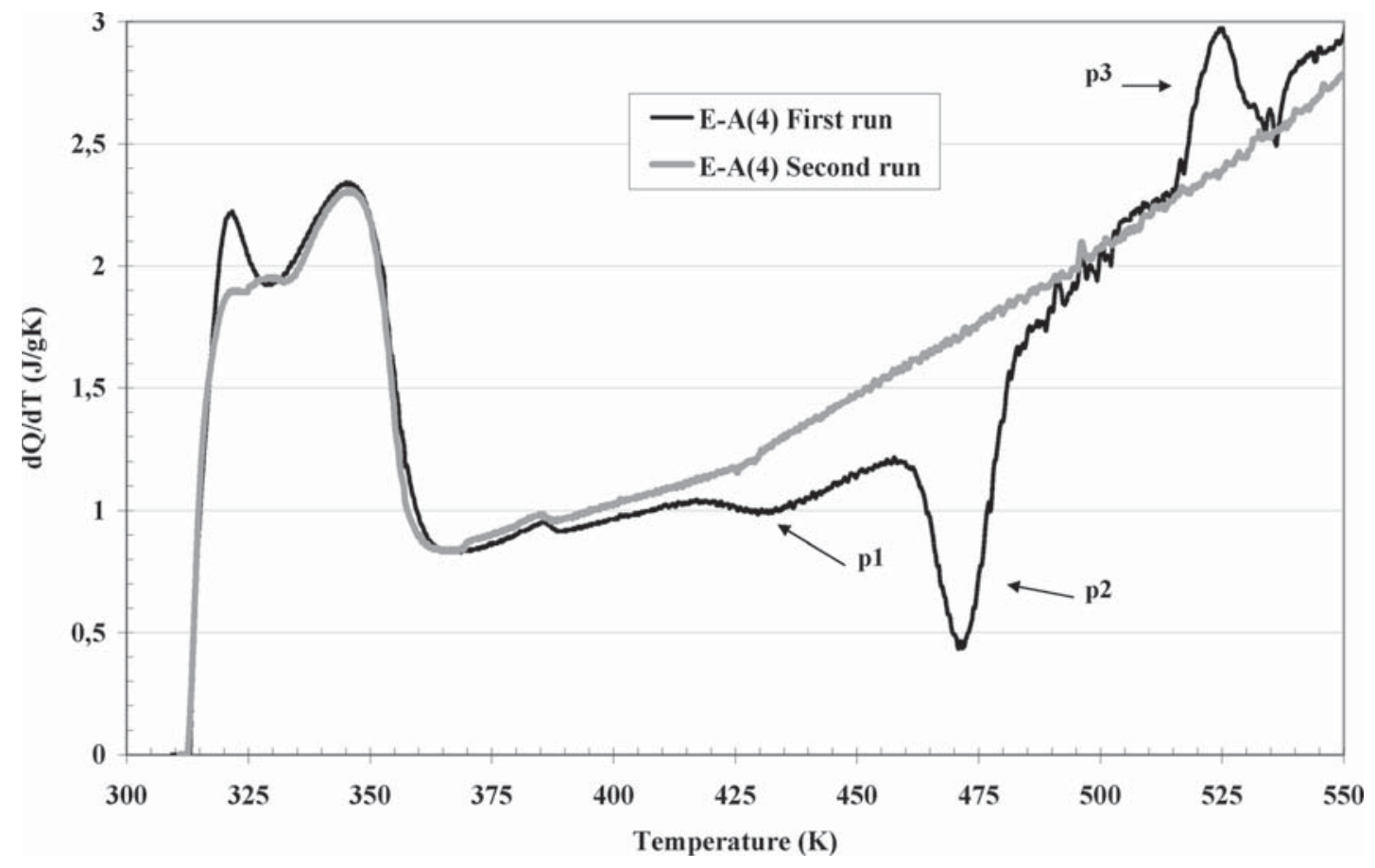

Figure 9 DSC results (first and second runs) for the EVA-ADC (4 phr) binary mixture.

of ADC corresponded mainly to the first process, the heat $\left(\mathrm{J} / \mathrm{g}_{\text {sample }}\right)$ of the first exothermic process ( $\left.\mathrm{p} 1\right)$ was at a minimum for the concentration of ADC (Table VII), as was the peak temperature. On the other hand, the heat corresponding to the second exothermic process $(\mathrm{p} 2)$ increased strongly and almost line- arly with the amount of ADC in the sample. Thus, the decomposition of the ADC in the sample with 4 phr of ADC (Fig. 9) showed a behavior similar (in the relative intensity of $\mathrm{p} 1, \mathrm{p} 2$, and $\mathrm{p} 3$ ) to that observed previously for the pure ADC (Fig. 2). The reaction heat corresponding to the third event (p3) increased with

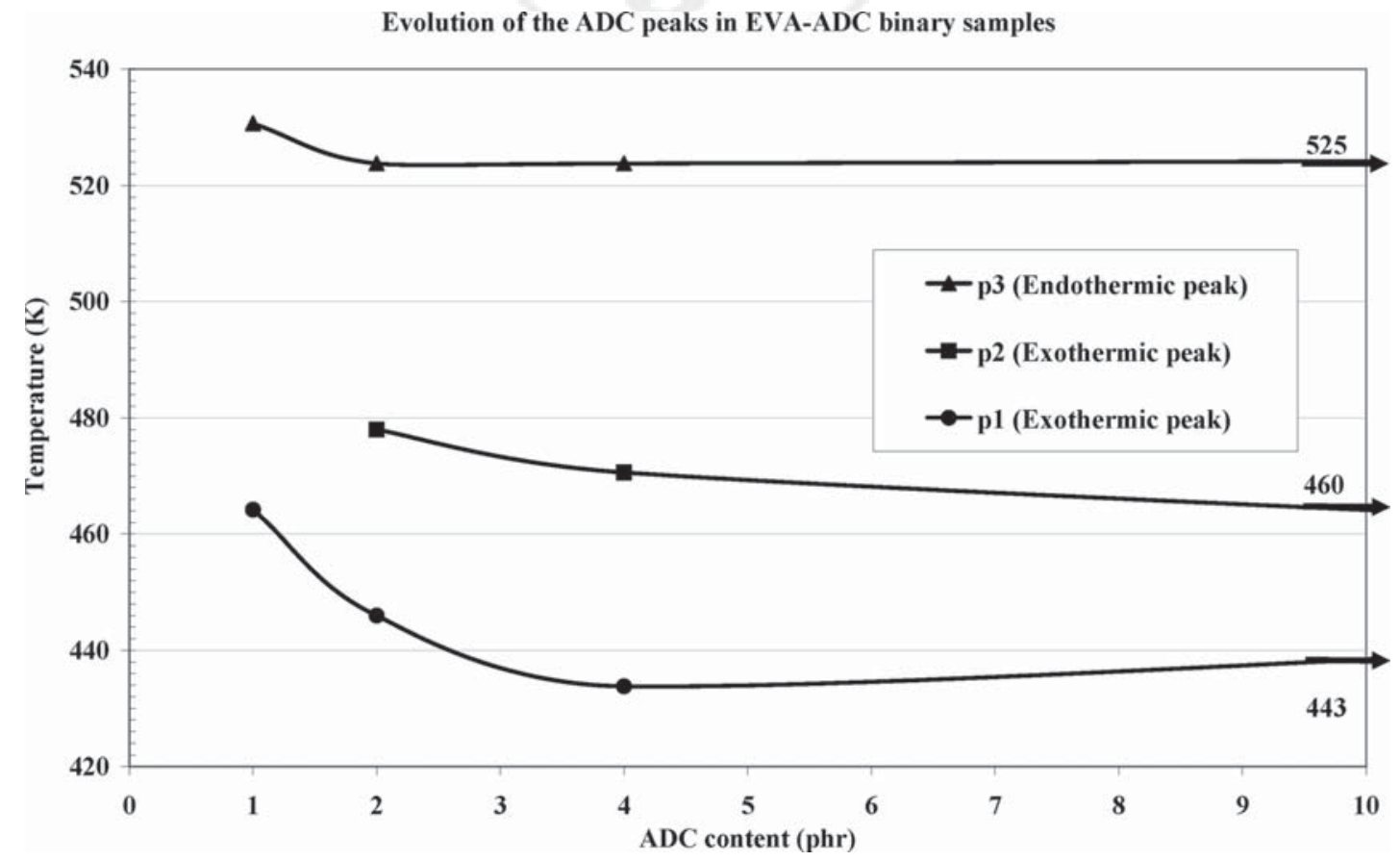

Figure 10 Evolution of the peak temperatures for ADC thermal decomposition in the EVA-ADC samples. 
TABLE VI

DSC Results (First Run) of Pure PE, Binary PE-ADC Mixtures and Ternary PE-ADC-ZnO Mixture

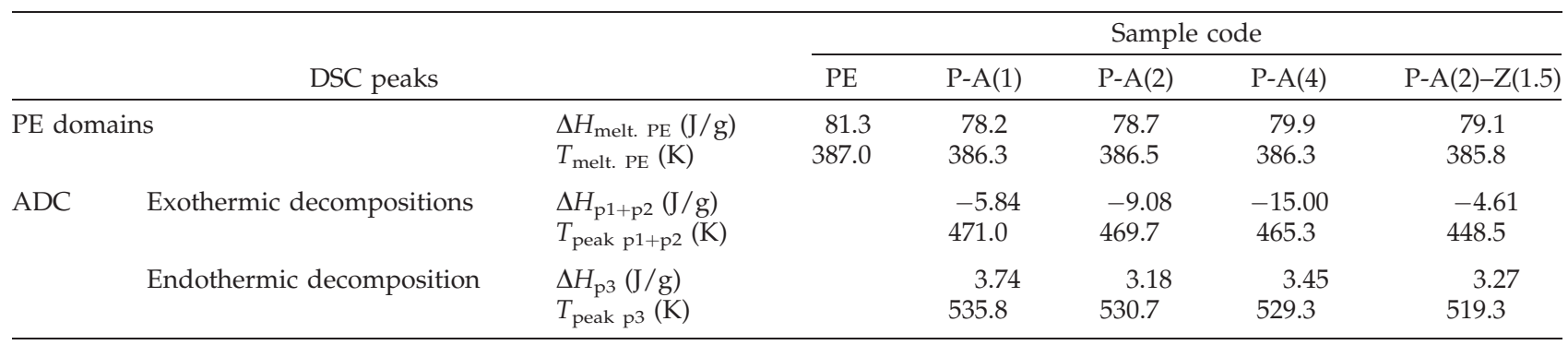

ADC content but at a rate lower than that corresponding to the linear trend.

\section{DSC of second consecutive runs}

DSC curves for the second consecutive run of PE-ADC mixtures showed almost no changes in peak temperature for the melting process of PE, compared with the first run, although a certain modification of the slope with a shoulder at the low-temperature tail was observed. Therefore, the foamed polymer maintained a similar degree of crystallinity after foaming in the DSC capsule.

Taking into account the second consecutive heating run of the EVA mixtures, the first peak for EVA contribution appeared at the same temperature but underwent a notable decrease in height and total area in the same way as what occurred in the pure EVA. ${ }^{18}$ The second and third peaks coincided (temperature and area) with those in the first run. Therefore, the transition and melting processes and crystallinity for the EVA copolymer apparently did not undergo any modification as a consequence of the foaming process.

It was also observed that for all the second-run experiments, no additional peaks appeared, indicat- ing that ADC was consumed completely during the first run

On the other hand, the base lines after the polymer peaks for both runs of each sample were very similar. Therefore, the base line slope should depend mainly on the gas that continued to be encapsulated in the sample and the inert components of the ADC, certifying the closed-cell structure of this kind of foam.

\section{Physical properties of the foamed samples}

To confirm the effect of the foaming reaction with different concentration of ADC, samples were processed in a heated plate press, and the density of the final foamed product was determined. These results are shown in Table VIII. Obviously, as the density values indicate, the extension of the foaming process increased with the concentration of ADC. The decreasing of the density with ADC concentration in the sample was more pronounced for EVA than for PE, showing the effect of the lower melt viscosity of the EVA and the possibility of a different reaction path and, therefore, gas evolution.

TABLE VII

DSC Results (First Run) for Pure EVA, Binary EVA-ADC Mixtures, and Ternary EVA-ADC-ZnO Mixture

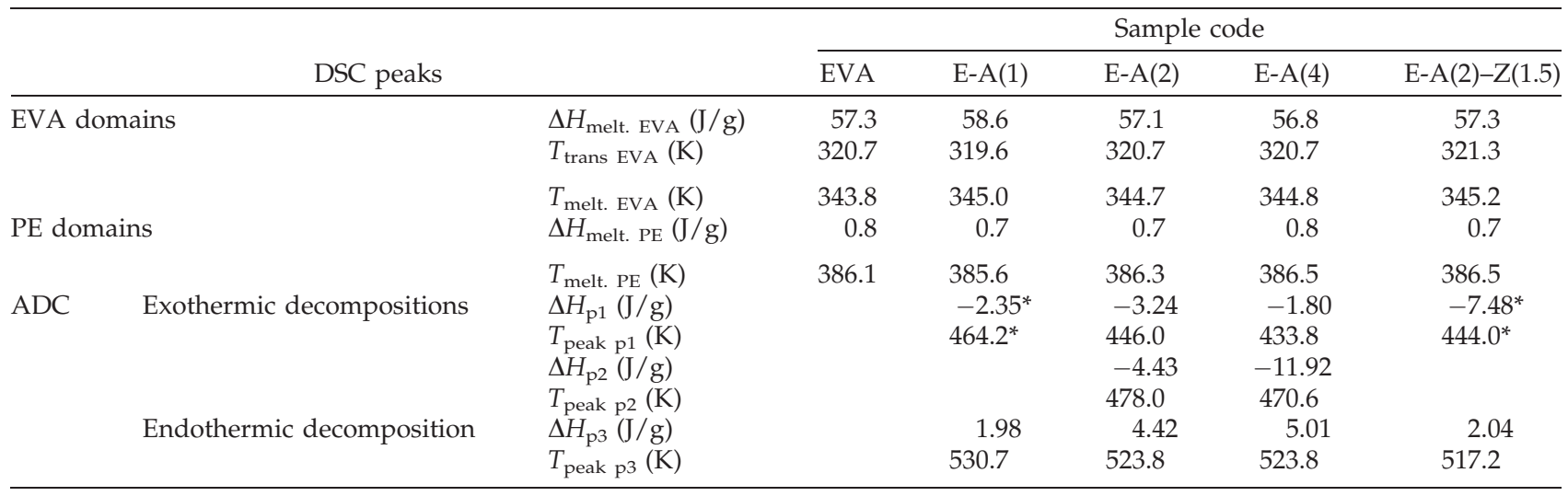

\footnotetext{
* Corresponding to p1 + p2 ADC peaks.
} 
TABLE VIII

Density of Pure PE, EVA, Binary PE-ADC, and EVAADC Mixtures and Ternary PE-ADC-ZnO and EVAADC-ZnO mixtures

\begin{tabular}{lc}
\hline \multicolumn{1}{c}{ Sample } & Density $\left(\mathrm{g} / \mathrm{cm}^{3}\right)$ \\
\hline PE & 0.923 \\
P-A $(1)$ & 0.430 \\
P-A(2) & 0.351 \\
P-A(4) & 0.282 \\
P-A(2)-Z(1.5) & 0.375 \\
EVA & 0.938 \\
E-A(1) & 0.404 \\
E-A(2) & 0.337 \\
E-A(4) & 0.205 \\
E-A(2)-Z(1.5) & 0.361 \\
\hline
\end{tabular}

Pressed samples at $175^{\circ} \mathrm{C}$ for $10 \mathrm{~min}$.

\section{Accelerating agent effect (ternary samples)}

F11 Figure 11 shows the DSC curves of a ternary mixture of PE, ADC (2 phr), and $\mathrm{ZnO}$ (1.5 phr) used as an accelerating agent (kicker). The results of these DSC experiments are also listed in Table VI. The effect of the zinc oxide in the sample was to reduce the thermal decomposition temperature of the azodicarbonamide from 470 to $449 \mathrm{~K}$ for the primary exothermic decomposition and from 531 to $519 \mathrm{~K}$ for the secondary endothermic decomposition (Figs. 4 and 11).

DSC curves for the ternary mixture E-A(2)-Z(1.5)

F12 are shown in Figure 12. The curve obtained for the first run showed only one exothermic peak, corresponding to the primary decompositions of the ADC at $444 \mathrm{~K}$ (Table VII). Therefore, with the presence of an accelerating agent, the two exothermic peaks in sample E-A(2), at 446 and $478 \mathrm{~K}$ (Fig. 8) merged. In contrast, the temperature for the endothermic peak shifted from 524 to $517 \mathrm{~K}$.

It was found that $\mathrm{ZnO}$ had no influence on the baseline slope in both the $\mathrm{P}-\mathrm{A}(2)-\mathrm{Z}(1.5)$ and the $\mathrm{E}-\mathrm{A}(2)-$ $\mathrm{Z}(1.5)$ samples.

The density of the foamed product (Table VIII) of samples P-A(2)-Z(1.5) and E-A(2)-Z(1.5) was higher than that measured for the corresponding samples without $\mathrm{ZnO}$. Therefore, in the presence of $\mathrm{ZnO}$ there seemed to be a lower yield of the foaming reaction. The higher melt viscosity of the polymer at the lower decomposition temperatures produced by the kicker, the density of the $\mathrm{ZnO}$ itself, and its possible effect on the reaction mechanism and gases evolution may account for this effect.

\section{CONCLUSIONS}

The pure ADC studied showed an exothermic primary decomposition reaction at 443 and $460 \mathrm{~K}$, followed by an endothermic secondary reaction at $525 \mathrm{~K}$.

In the binary samples PE-ADC and EVA-ADC, the temperature and heat of fusion (and therefore the degree of crystallinity) of the polymeric matrix (PE or EVA) were not modified by the presence of the foaming agent. However, the polymeric matrix delayed the

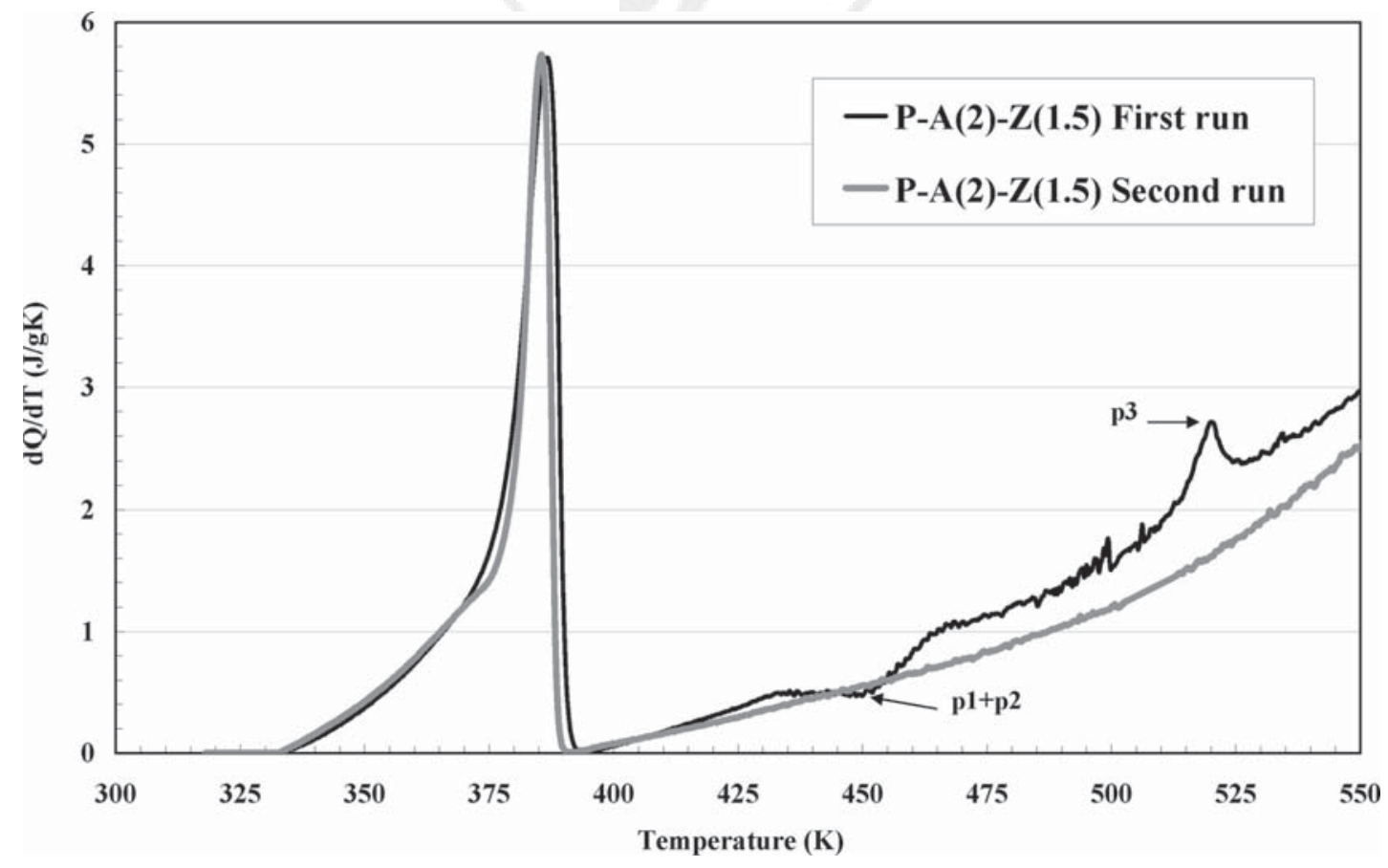

Figure 11 DSC results (first and second runs) for the ternary mixture PE-ADC (2 phr)/ZnO (1.5 phr). 


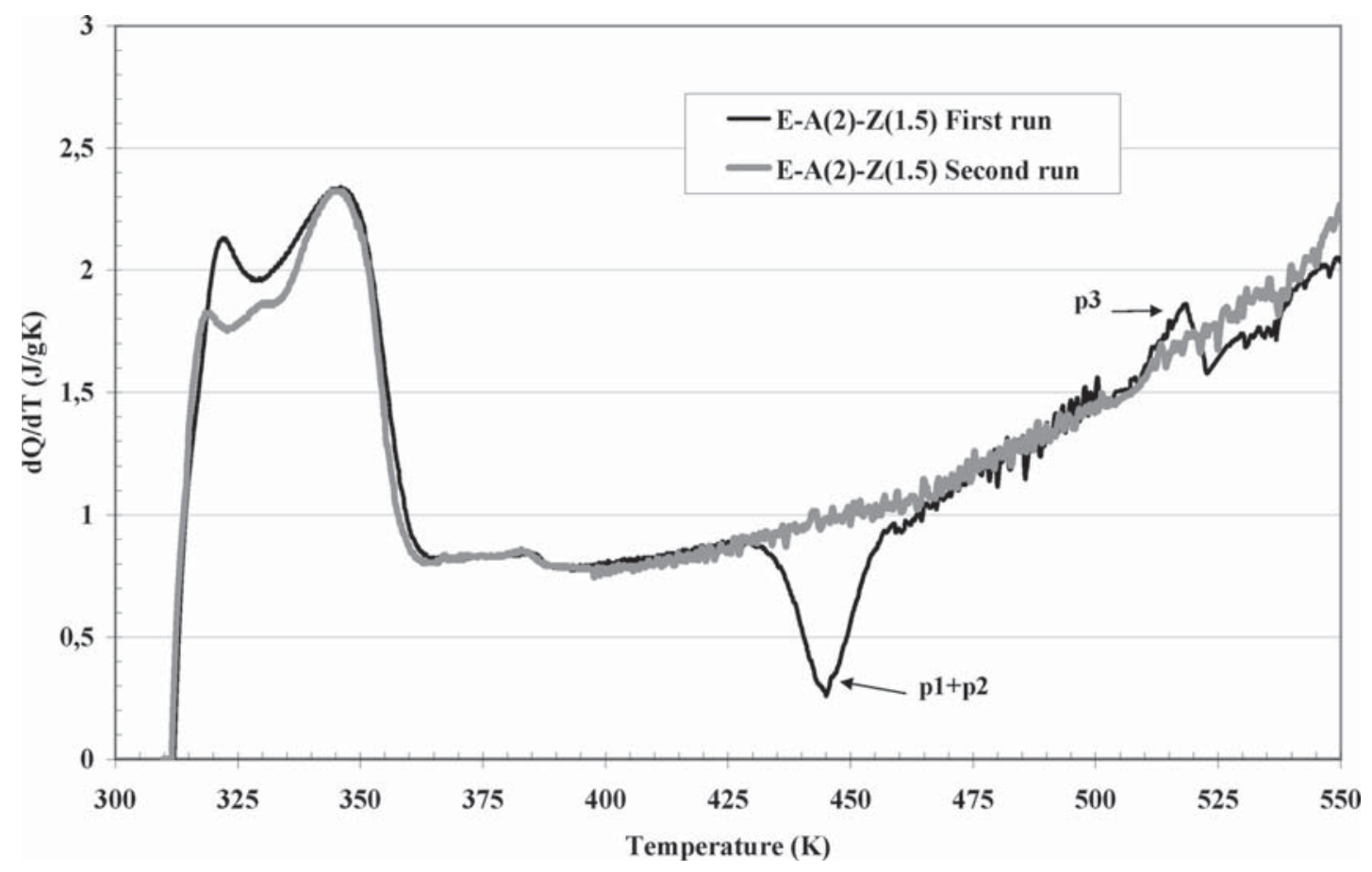

Figure 12 DSC results (first and second runs) for the ternary mixture EVA-ADC (2 phr)/ZnO (1.5 phr).

thermal decomposition of the ADC because of physical and chemical interactions. In addition, these peak temperatures decreased when the ADC content of the binary mixtures was increased because of an autoaccelerating effect on the decomposition of ADC. The peak temperatures of the ADC decomposition could also be reduced by using a kicker such as $\mathrm{ZnO}$.

The different evolutions of the reaction heats of the decomposition of ADC depending on the polymeric matrix used (PE or EVA) may indicate a different mechanism of decomposition of the ADC in both samples. The effects of the foaming process were more pronounced when EVA was used as polymeric matrix, as confirmed by the lower density found for the EVA-ADC foamed samples.

\section{References}

1. Léva, I. G.; Nyitrai, Z. S.; Meszlényi, G. Models Chem 1998, $135,885$.

2. Bhatti, A. S.; Dollimore, D. Thermochim Acta 1984, 76, 273.

3. Quinn, S. (Bayer). Plast Addit Compounding 2001, May, 16.

4. Stevens and Emblem. Ind Chemist 1951, 27, 391.
5. Lober F. Angew. Chem 1952, 64, 65.

6. Bhatti A.S.; Dollimore D. Thermochim Acta 1984, 76, 63.

7. Throne, J. L. Thermoplastic Foams; Sherwood Publishers: $\mathrm{OH}$, 1996.

8. Klempner, D.; Frisch, K. C. Polymeric Foams; Oxford University Press: New York, 1991.

9. Morisaki, S.; Naito, M. J Hazard Mater 1981, 5, 49.

10. Kong, Y.; Hay, J. N. Polymer 2002, 43, 3873.

11. Pinoit, D.; Prud'homme, R. E. Polymer 2002, 43, 2321.

12. Kong, Y.; Hay, J. N. Eur Polym J 2003, 39, 1721.

13. Mathot, V. B. F. Calorimetry and Thermal Analysis of Polymers; Hanser/Gardner Publications: Cincinnati, OH, 1993.

14. Bershtein, V. A.; Egorov, V. M. Differential Scanning Calorimetry of Polymers; Ellis Horwood: Chichester, UK, 1994.

15. Adamovskya, S. A.; Minakovb, A. A.; Schick, C. Thermochim Acta 2003, 403, 55.

16. Songa, M.; Hourstonb, D. J.; Pollocka, H. M.; Schäferb, F. U.; Hammichea, A. Thermochim Acta 1997, 304, 335.

17. Jung, D. H.; Moon, I. K.; Jeong, Y. H. J Korean Phys Soc 1999; 35, 1359.

18. Marcilla, A.; Reyes, J. A.; Sempere, F. J. Polymer 2001, 42, 5343.

19. Sempere, F. J. Ph.D. Dissertation, University of Alicante, Spain, 2002.

20. Marcilla, A.; Sempere, F. J.; Reyes, J. A. Polymer 2004, 45, 4977.

21. Cronin, J. L.; Nolan, P. F. J Hazard Mater 1987, 14, 293. 